\title{
A New Pathway of Staphylococcal Pathogenesis: Apoptosis-Like Death Induced by Staphopain B in Human Neutrophils and Monocytes
}

\author{
Jan Smagur ${ }^{a} \quad$ Krzysztof Guzik $^{b} \quad$ Lukasz Magiera $^{\mathrm{b}}$ Malgorzata Bzowska ${ }^{\mathrm{b}}$ \\ Milosz Gruca ${ }^{a}$ Ida B. Thøgersen ${ }^{c}$ Jan J. Enghild ${ }^{c}$ Jan Potempa ${ }^{a}$ \\ Departments of ${ }^{\mathrm{a}}$ Microbiology and ${ }^{\mathrm{b}}$ Immunology, Faculty of Biochemistry, Biophysics and Biotechnology, \\ Jagiellonian University, Krakow, Poland; ' Department of Molecular Biology, University of Aarhus, Aarhus, Denmark
}

\begin{abstract}
Key Words
Apoptosis · Necrosis · Phagocytosis · Protease •

Staphylococcus aureus • Inflammation • Infection •

Immunoglobulin $\cdot$ Receptor
\end{abstract}

\begin{abstract}
Circulating neutrophils and monocytes form the first line of cellular defense against invading bacteria. Here, we describe a novel and specific mechanism of disabling and eliminating phagocytes by Staphylococcus aureus. Staphopain B (SspB) selectively cleaved CD11b on phagocytes, which rapidly acquired features of cell death. SspB-treated phagocytes expressed phosphatidylserine as well as annexin I and became permeable to propidium iodide, thus demonstrating distinctive features of both apoptosis and necrosis, respectively. The cell death observed was caspase and Syk tyrosine kinase independent, whilst cytochalasin D efficiently inhibited the staphopain-induced neutrophil killing. Neutrophil and monocyte cell death was not affected by integrin clustering ligands (ICAM-1 or fibrin) and was prevented, and even reversed, by lgG. This protective effect was dependent on the Fc fragment, collectively suggesting cooperation of the CD16 receptor and integrin Mac-1 (CD11b/CD18). We conclude that SspB, particularly in the presence of staphylococcal protein A, may reduce the number of functional phagocytes at infection sites, thus facilitating colonization and dissemination of S. aureus.

Copyright @ 2008 S. Karger AG, Basel
\end{abstract}

\section{KARGER}

Fax +41613061234

E-Mail karger@karger.ch

www.karger.com
(C) 2008 S. Karger AG, Basel

1662-811X/09/0012-0098\$26.00/0

Accessible online at:

www.karger.com/jin

\section{Introduction}

Neutrophils and monocytes play a significant role in the phagocytosis and killing of invading microorganisms. For this purpose, these cells possess a variety of receptors, along with enzymatic and oxidative apparatus, that enable them to engulf and subsequently kill phagocytosed bacteria [1]. The effective clearance of microbes by the circulating cells of the host innate defense system is crucial in combating infection. The importance of neutrophils in protecting against invading staphylococci is primary, and indeed neutropenic patients, or those suffering from granulomatous disease, are particularly susceptible to Staphylococcus aureus infections [2].

Phagocytosis is mediated by specialized plasma membrane receptors that recognize specific ligands and opsonins on the surface of particles to be engulfed. Fc $\gamma \mathrm{R}$ and $\mathrm{CD} 1 \mathrm{~b} / \mathrm{CD} 18$ integrin (Mac-1, CR3, $\alpha \mathrm{M} \beta 2$ and Mo-1) are the best-characterized components engaged in the phagocytosis of particles (including bacteria) by neutrophils, monocytes and macrophages [3]. During phagocytosis, the specific interaction of $\mathrm{Fc} \gamma \mathrm{R}$ or $\mathrm{CD} 1 \mathrm{~b} / \mathrm{CD} 18$ integrin with IgG- or C3bi-opsonized particles induces the local clustering of receptors. This results in the phosphorylation of tyrosine residues in immunoreceptor tyrosinebased activation motifs of Fc $\gamma$ RIIA and the accessory $\gamma$ chain of Fc $\gamma$ RI and Fc $\gamma$ RIIIA. This is followed by subsequent activation of several downstream proteins, such as 
Src and Syk family kinases $[4,5]$. Fc $\gamma$ RIII (CD16) forms a functional surface complex with integrin CD11b/CD18, thus modulating a variety of processes, including cell activation, adhesion, phagocytosis and the regulation of oxidative burst [6-8].

S. aureus is a versatile pathogen responsible for both community- and hospital-acquired infections, ranging from relatively minor skin and wound infections to lifethreatening diseases, including arthritis, endocarditis, osteomyelitis, toxic shock syndrome and sepsis [9]. The treatment of $S$. aureus infections, which is already complicated by the high prevalence of methicillin-resistant strains, has been made even more problematic by the emergence of vancomycin-insensitive and even vancomycin-resistant isolates during the last 3 decades [10]. The versatile nature of $S$. aureus pathogenesis is inextricably linked to the vast arsenal of virulence factors encoded within its genome [11]. These factors cover many broad groups, including surface proteins that function as adhesion factors, extracellular proteins (e.g. toxins) and regulatory loci [12].

It has previously been shown that $S$. aureus is able to induce apoptosis and necrosis in a multitude of cell types, including endothelial cells [13], epithelial cells [14], monocytes [15] and lymphocytes [16, 17]. In addition, a large body of evidence suggests that extracellular toxins, including $\alpha$-toxin $[16,17]$, Panton-Valentine leukocidin [18] and toxic shock syndrome toxin [19], play a major role in this process. The apoptosis induced in circulating phagocytes by $S$. aureus, or its pore-forming toxins, is preferentially mediated by the mitochondrial pathway, although at higher toxin concentration it bears features of necrosis [17]. Consequently, the induced apoptosis involves the rapid disruption of mitochondrial homeostasis, cytochrome $c$ release and the sequential activation of caspase- 9 and caspase-3 followed by nuclear DNA fragmentation $[15,17,18]$. This type of apoptosis is regulated by members of the Bcl-2 family and not by those belonging to the death receptor pathway $[16,18]$.

$S$. aureus secretes 4 major proteases: a serine protease (SspA or V8 protease), 2 cysteine proteases (staphopain A, ScpA, and staphopain B, SspB) and a metalloprotease (aureolysin, Aur) [20]. The significance of these proteases in staphylococcal pathogenicity has been documented in several studies, but their role in apoptosis or necrosis has not been investigated thus far. Here, we report that SspB is able to induce a mixed necrotic- and apoptotic-like form of cell death in human neutrophils and monocytes. Our data reveal that cell death is initiated by an SspB-mediated reduction in the surface expression of $\mathrm{CD} 11 \mathrm{~b} /$
CD18 (Mac-1, CR3, $\alpha \mathrm{M} \beta 2$ and Mo-1) integrins on both cell types. This observation correlates with CD11b/CD18 receptor engagement in the control of neutrophil apoptosis at the molecular level [21-23].

\section{Materials and Methods}

\section{Cells}

Peripheral blood mononuclear cells were isolated from citratetreated human peripheral blood obtained from healthy donors using standard density gradient centrifugation. Peripheral blood mononuclear cells were further subjected to counterflow centrifugation, as described previously [15], to isolate fractions highly enriched in monocytes (85-95\% CD14 positive; clone: TÜK4; DakoCytomation Denmark A/S, Glostrup, Denmark). Monocytes were either used immediately upon isolation or precultured for $2 \mathrm{~h}$ under adherent conditions (adherent monocytes).

Polymorphonuclear cells (neutrophils) were isolated from erythrosediments by sedimentation in $1 \%$ polyvinyl alcohol solution (Merck, Hohenbrunn, Germany) for $20 \mathrm{~min}$ at room temperature. Neutrophils were collected from the upper layer, and contaminating erythrocytes were lysed with distilled water for 20 s. Pappenheim staining indicated that cells isolated in this way were at least $90 \%$ homogenous. Neutrophils were used immediately after harvesting.

Detection of Cell Death: Flow Cytometry and DNA Laddering

The externalization of phosphatidylserine (PS) and annexin (Anx) I to the cell surface was assessed by staining PS with FITClabeled AnxV and AnxI with FITC-labeled anti-AnxI monoclonal antibodies (both from BD Pharmingen, Franklin Lakes, N.J., USA). In parallel, the exclusion of propidium iodide (PI) was determined according to the manufacturer's recommendations (Annexin V-FITC kit; Bender MedSystems, Vienna, Austria). Cells were analyzed with a FACScan flow cytometer (Becton Dickinson, Franklin Lakes, N.J., USA). Furthermore, cellular morphology was evaluated for features of apoptosis or necrosis using bright-field phase contrast microscopy.

To detect ladder-like DNA fragmentation (a typical feature of advanced apoptosis), neutrophils or monocytes were suspended in medium containing $1 \%$ BSA and $\operatorname{SspB}(12.5,25,50,75$ and 100 $\mathrm{nM})$ and incubated for $24 \mathrm{~h}$ under standard culture conditions to allow the development of apoptosis. Control cells suspended in medium containing $1 \%$ BSA were incubated in parallel. Genomic DNA was then isolated and gel electrophoresis performed as described previously [15].

\section{Purification and Activation of $\operatorname{Ssp} B$}

$\mathrm{SspB}$ was purified from $S$. aureus strain BC10 culture supernatant using a modified method of that described by Arvidson et al. [24]. Protein purity was checked by SDS-PAGE, whilst the amount of active enzyme was determined by active site titration using E-64 (L-trans-epoxysuccinyl-leucylamide-(4-guanido)-butane). A $25 \mathrm{M}$ excess of E-64 (10 $\mu \mathrm{M}$ final concentration) was used to irreversibly inactivate $\mathrm{SspB}(12 \mathrm{~h}$ incubation at room temperature).

As the cysteine protease $S \mathrm{spB}$ requires pretreatment with a reducing agent to attain full activity, the stock solution of SspB was 
diluted in $100 \mathrm{~mm}$ Tris-HCl, 5 mM EDTA, pH 7.6, supplemented with $2 \mathrm{mM}$ dithiothreitol to a final enzyme concentration of 400 $\mathrm{nM}$, and incubated at $37^{\circ} \mathrm{C}$ for $15 \mathrm{~min}$. Activated SspB was then diluted 1:1 (v/v) with culture media (200 nM working concentration) and further diluted to appropriate final concentrations using media and cell suspensions.

\section{Treatment of Cells with Protease}

Fresh neutrophils and monocytes $\left(15 \times 10^{6} / \mathrm{ml}\right)$ were suspended in RPMI 1640 supplemented with L-glutamine ( $2 \mathrm{mM})$, gentamycin $(50 \mu \mathrm{g} / \mathrm{ml})$, and either BSA $(1-2 \%)$ or human serum (2\%). Cells were incubated for $75 \mathrm{~min}$ at $37^{\circ} \mathrm{C}$ in a humidified atmosphere containing $5 \% \mathrm{CO}_{2}$, along with either fully active $\mathrm{SspB}$, active site-blocked SspB or catalytically inactive SspB (Cys24Ala mutant; final concentration $100 \mathrm{nM}$ ). The appropriate untreated controls were also performed in parallel to these incubations. Neutrophil and monocyte samples were then washed once in complete medium, harvested by centrifugation $(280 \mathrm{~g}, 10 \mathrm{~min}$, $4^{\circ} \mathrm{C}$ ) and resuspended in an appropriate medium (dependent on the experiment type).

In the case of adherent monocytes, the enzyme solution in the medium was added directly to the cell monolayer. After incubation, cells were washed with PBS to remove SspB. Next, cells were harvested gently using a rubber policeman, centrifuged $(280 \mathrm{~g}, 10$ $\min , 4^{\circ} \mathrm{C}$ ) and resuspended in an appropriate medium (dependent on the experiment type).

Immunofluorescence Staining of Neutrophils and Monocytes, and Flow-Cytometric Analysis

For antibody staining, cells $\left(1 \times 10^{6} /\right.$ sample $)$ were resuspended in medium containing 1\% FCS followed by incubation with phycoerythrin-conjugated anti-CD11b mAb (clone ICRF44; BD Pharmingen) or phycoerythrin-conjugated anti-CD16 mAb (clone DJ130c; Dako A/S) at $4^{\circ} \mathrm{C}$ for $30 \mathrm{~min}$. After washing with medium with $1 \%$ FCS, cells were resuspended in $400 \mu \mathrm{l}$ of the same medium and analyzed by flow cytometry. Flow-cytometric analysis was performed using a FACScan cytometer (Becton Dickinson). Forward and side scatter signals were used to gate for morphologically normal cells, with $10^{4}$ cells acquired per run. Analysis of the generated data was performed using the CellQuest program to determine the percentage and mean fluorescence intensity of positive cells.

\section{Effect of Inhibitors, IgG and IgG Fc Fragments on}

SspB-Induced Neutrophil Death

Human IgG (11 mg/ml; ART, Athens, Ga., USA), Fc fragments of IgG (7 mg/ml; ART), cytochalasin D (100 $\mu \mathrm{M}$; Sigma, St. Louis, Mo., USA), zVAD-fmk (75 and $150 \mu \mathrm{M}$; Becton Dickinson) and piceatannol (20 $\mu \mathrm{M}$; Sigma) were added to neutrophil suspensions, and samples were preincubated for $15 \mathrm{~min}$. SspB was then added to a final concentration of $100 \mathrm{nM}$, and the suspension was incubated for an additional $75 \mathrm{~min}$ at $37^{\circ} \mathrm{C}$ in a humidified atmosphere containing $5 \% \mathrm{CO}_{2}$. In parallel, the appropriate untreated control samples were prepared and incubated in an identical manner. After incubation, cells were treated as described above.

\section{Human Serum Fractionation}

Fractions were obtained from human serum pooled from 5 healthy donors. Proteins were precipitated at 25, 50 and $80 \%$ am- monium sulfate saturation, with continuous stirring at $4^{\circ} \mathrm{C}$. Protein precipitate was collected by centrifugation $(20,000 \mathrm{~g}, 40 \mathrm{~min}$, $4^{\circ} \mathrm{C}$ ), resuspended in distilled water and dialyzed for $24 \mathrm{~h}$ with 3 changes against a large volume of distilled water. Protein concentrations were determined using a bicinchoninic acid assay kit (Sigma) according to the manufacturer's protocol, and diluted in medium supplemented with L-glutamine and gentamycin to 20 $\mathrm{mg} / \mathrm{ml}$ final concentrations. The effect of SspB (100 nM) on neutrophils was assayed in the presence of individual fractions added to a final protein concentrations of $8 \mathrm{mg} / \mathrm{ml}$. Cells were stained with FITC-labeled AnxV and PI according to the manufacturer's recommendations (Annexin V-FITC kit; Bender MedSystems). A fraction, precipitated at $50 \%$ ammonium sulfate saturation, which blocked the lethal effect of SspB most efficiently, was loaded onto a Mono-Q FPLC column (Amersham Pharmacia, Piscataway, N.J., USA) equilibrated with $20 \mathrm{~mm}$ Tris- $\mathrm{HCl}, \mathrm{pH} 7.9$ at a flow rate of $1 \mathrm{ml} / \mathrm{min}$. Proteins were eluted with a $\mathrm{NaCl}$ gradient from 0 to $1 \mathrm{M}$ developed in $35 \mathrm{~min}$ at $1 \mathrm{ml} / \mathrm{min}$. Obtained fractions were dialyzed against distilled water, diluted in medium to appropriate concentrations, and their protective effect against neutrophils death (induced by SspB) determined as described above. The fraction which blocked the lethal effect of SspB on neutrophils most efficiently was then analyzed by SDS-PAGE. This protein was then transferred to a polyvinylidene difluoride membrane, and was subjected to $\mathrm{N}$-terminal amino acid sequence analysis using automated Edman degradation (a Procise 494-HT protein sequencer). An N-terminal sequence of EVQLVESGG was returned, revealing the protein to be human IgG.

\section{Preparation of Protein A-Treated Human Serum}

Protein A-Sepharose CL-4B (110 mg; Pharmacia Fine Chemicals, Uppsala, Sweden) was equilibrated in $0.5 \mathrm{ml}$ of medium supplemented with L-glutamine and gentamycin for $3 \mathrm{~h}$ with gentle stirring every $20 \mathrm{~min}$. Beads were then washed twice in $0.5 \mathrm{ml}$ of fresh media (centrifuged $500 \mathrm{~g}, 10 \mathrm{~min}$, room temperature) before being resuspended in a final volume of $0.5 \mathrm{ml}$ of further fresh media. Heat-inactivated human serum $(0.5 \mathrm{ml}$ of serum pooled from 5 donors) was added to the bead suspensions and incubated for $12 \mathrm{~h}$ at room temperature with continuous gentle stirring. After incubation, beads were removed by centrifugation $(500 \mathrm{~g}, 10 \mathrm{~min}$, room temperature), and supernatant was collected and diluted in medium supplemented with L-glutamine and gentamycin to a $4 \%$ final concentration. In parallel, a sample of human serum was incubated with Sepharose CL-4B (Pharmacia Fine Chemicals) in exactly the same conditions and used as a control for the nonspecific binding of proteins to the matrix.

\section{Statistics}

All data are presented as means with standard deviation (SD). All statistics were calculated using GraphPad Prism (version 3.1; GraphPad, San Diego, Calif., USA). Nonparametric tests were applied throughout and the calculated $p$ values are given in the relevant figures. Each reflects a statistically significant difference in comparison to the appropriate control of untreated cells, unless indicated otherwise. 


\section{Results}

In the Absence of Human Serum, SspB Induces Cell

Death in Human Neutrophils and Monocytes in a

Proteolytic Activity-Dependent Manner

An early feature of apoptosis is the externalization of the anionic phospholipids - PS and AnxI. Thus, we subjected human neutrophils and monocytes to treatment with purified SspB to determine if it had a role in the expression of these components. We found that after $75 \mathrm{~min}$ of treatment with $100 \mathrm{nM} \mathrm{SspB,50 \%}$ of cells expressed PS, as indicated by cell staining with FITC-conjugated AnxV. Among the PS-expressing cells, $20-65 \%$ were also permeable to PI, indicating a compromised cell membrane (fig. 1). Relatively high SD values were observed for SspBexposed neutrophils and likely resulted from a differential susceptibility to SspB treatment of the cells derived from individual donors. Significantly, in the presence of $1-2 \%$ of human serum, SspB did not induce AnxV and PI staining in neutrophils and monocytes, despite the fact that serum at this concentration had no effect on the proteolytic activity of SspB (data not shown).

The role of the SspB activity in the induction of neutrophil death was further investigated using an irreversible SspB inhibitor (E-64) as well as an inactive recombinant form of the enzyme with the catalytic cysteine residue converted to alanine (C24A). As shown in figure $1 d$, C24A staphopain had no effect on human neutrophils. In keeping with this, preincubation of SspB with E-64 also significantly reduced the pro-death activity of the protease. Together, these results clearly show that the increase in PS and AnxI expression in neutrophils and monocytes by $\mathrm{SspB}$ is dependent on its proteolytic activity. This suggests that a proteolytic modification of cell surface proteins is responsible for the observed phenomenon.

Interestingly, the effect of SspB was cell specific and entirely limited to neutrophils and monocytes. Protease treatment had no effect on other cell types, such as human monocyte-derived macrophages, Jurkat T lymphocytes, endothelial cell line (Eahy 926), 293-Hek cells (human embryonal kidney), HaCAT (human keratinocyte cell line), U937 cells (human premonocytic cell line) and fibroblasts (data not shown).

\section{SspB Has Divergent Effects on the Fragmentation of}

DNA in Neutrophils and Monocytes

The exposure of PS on cell surfaces is an early and, in some circumstances, reversible feature of apoptosis [25]. To test the possibility that SspB may affect the latter stag- es of apoptosis, we allowed cells to undergo spontaneous apoptosis and analyzed the integrity of DNA from SspBtreated and untreated neutrophils and monocytes. Cells were exposed to SspB at different concentrations for $24 \mathrm{~h}$, followed by the electrophoretic analysis of DNA integrity. Interestingly, DNA fragmentation in SspB-treated, aged neutrophils was clearly inhibited (fig. 2, PMN) and an effect was most visible at higher enzyme concentrations. In contrast to neutrophils, SspB induced extensive apoptotic DNA fragmentation in monocytes in an inverse concentration-dependent manner (fig. 2, Mo). Significantly, SspB-induced apoptotic DNA laddering was comparable to that observed in monocytes following phagocytosis of live S. aureus [15].

In light of these results, it is evident that the treatment of neutrophils or monocytes with SspB triggered an atypical apoptotic-like form of death. In this atypical state some early features of apoptosis were not followed by DNA fragmentation, but instead cells were shunted towards necrotic death as shown by the loss of plasma membrane integrity. Moreover, in neutrophils preincubated with SspB, we did not observe mitochondrial membrane potential loss (data not shown), which is an additional attribute typical of the intrinsic apoptotic pathway.

Human Blood Serum Reverses SspB-Induced Exposure of PS and AnxI on the Outer Leaflet of the Neutrophil Cytoplasmatic Membrane

Inspired by the observed lack of $A n x V$ binding and PI staining of neutrophils incubated with SspB in the presence of human serum, we investigated the effect of serum on posttreatment exposure of PS and AnxI on neutrophils treated with the protease in medium containing BSA. A significant increase in PS and AnxI in the outer leaflet of the cytoplasmic membrane was observed upon treatment with SspB (fig. 3a and b). However, this effect was totally reversed after $2 \mathrm{~h}$ of culturing washed cells in the presence of $2 \%$ human serum (fig. $3 c$ and d). After aging neutrophils for $12 \mathrm{~h}$, both SspB-treated and control cells show similar levels of PS and AnxI expression, which is characteristic of spontaneous apoptotic cell death (fig. 3e and f). An examination of SspB-treated neutrophils using contrast-phase microscopy excluded the possibility that this process was mediated via protease-induced cell lysis (data not shown). Together, these results clearly indicate that the SspB-induced exposure of PS and AnxI on neutrophils can be reversed by human serum. 

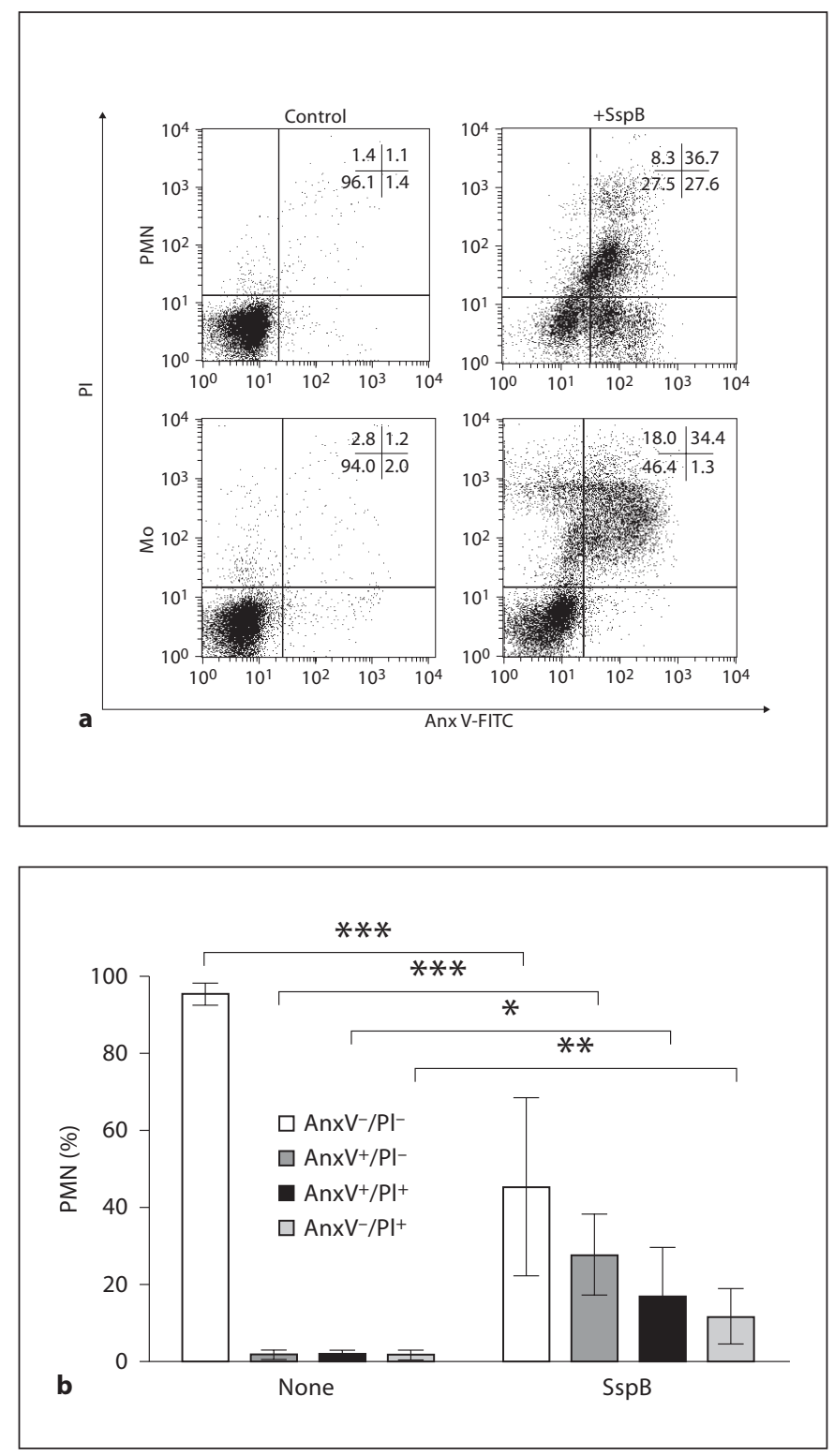

Fig. 1. SspB induces death in human neutrophils and monocytes in a proteolytic activity-dependent manner in the absence of human serum. Neutrophils (PMN) and monocytes (Mo) were treated with $100 \mathrm{nM} \mathrm{SspB}$ for $75 \mathrm{~min}$ at $37^{\circ} \mathrm{C}$ in the presence of $1 \% \mathrm{BSA}$ and then washed with culture media to remove the enzyme. Control or treated cells were analyzed for externalization of PS and cell membrane permeability by staining with FITC-labeled AnxV and PI, respectively. Cells were analyzed by flow cytometry to determine the percentage of (1) healthy cells (AnxV-/PI-) negatively stained with both AnxV and PI, (2) cells expressing PS but with an intact plasma membrane (AnxV+/PI-), (3) cells with both externalized PS and a compromised membrane (AnxV+/PI+)
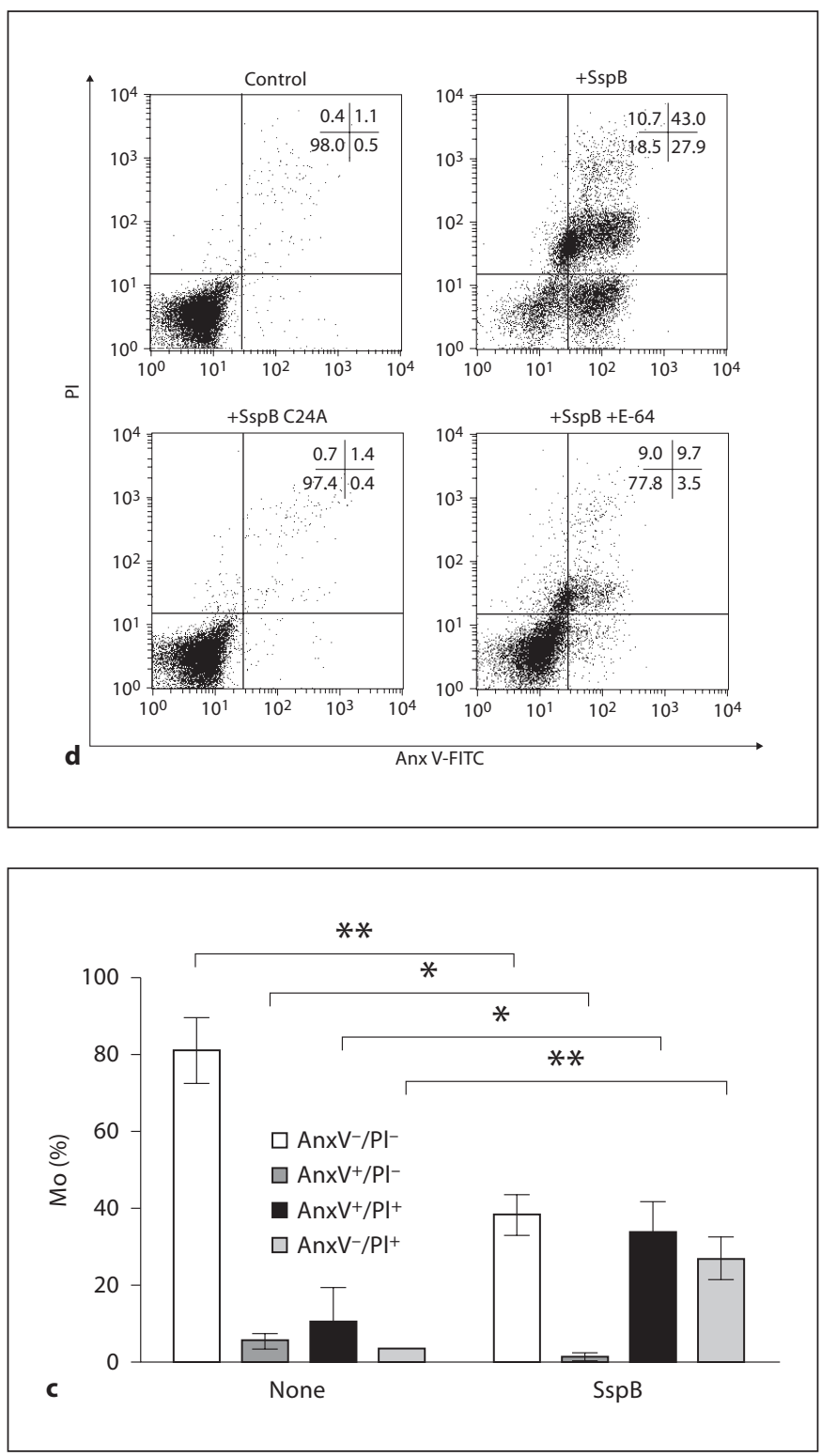

and (4) cells without external PS but positively stained with PI $(\mathrm{AnxV}-/ \mathrm{PI}+)$. The percentage of cells in each subpopulation counted in quadrants is shown in the insets of representative dot plots (a and $\mathbf{d})$. a Result of an experiment assessing the effect of active SspB (+SspB) on neutrophils (PMN) and monocytes (Mo). Bar graphs (b and $\mathbf{c}$ ) represent mean percentage values \pm SD of each cell subpopulation inferred from 7 experiments with neutrophils (b) and 3 with monocytes (c). ${ }^{*} \mathrm{p}<0.05 ;{ }^{* *} \mathrm{p}<0.01$; ${ }^{* *} \mathrm{p}<$ 0.001. d Effect of E-64-treated protease $(+\mathrm{SspB}+\mathrm{E}-64)$ and the inactive recombinant form of the protease (+SspB C24A) on neutrophils. 


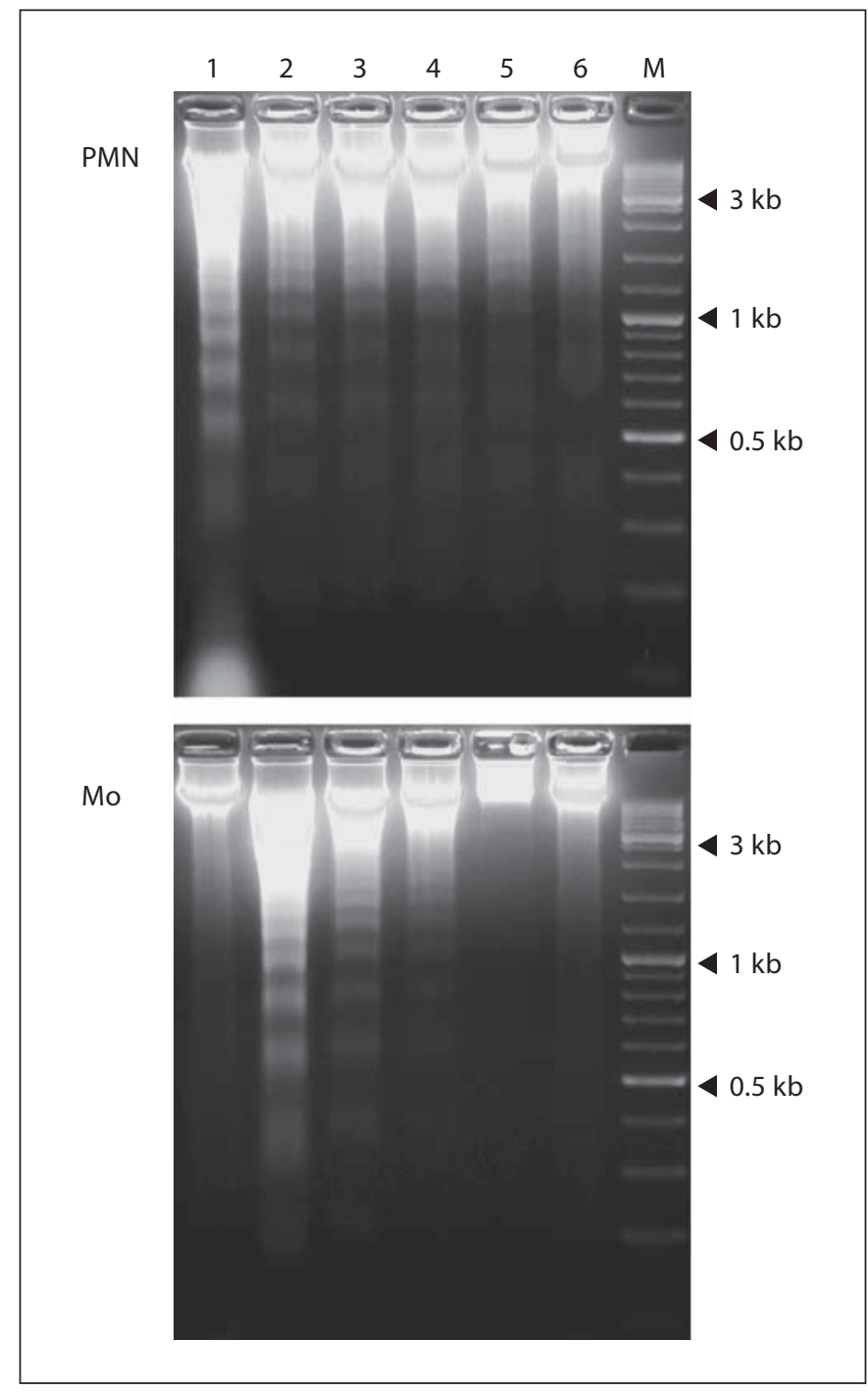

Fig. 2. Apoptotic DNA fragmentation in neutrophils and monocytes following treatment with $\mathrm{SspB}$. DNA isolated from neutrophils (PMN) and monocytes (Mo) cultured for $24 \mathrm{~h}$ in the presence of various concentrations of SspB (in medium with 1\% BSA) was subjected to electrophoretic analysis. Lane 1 = control cells; lanes 2-6 = cells incubated with 12.5, 25, 50, 75 and $100 \mathrm{nM} \mathrm{SspB,}$ respectively; $\mathrm{M}=\mathrm{DNA}$ size marker (O'GeneRuler ${ }^{\mathrm{TM}}$; Fermentas, Vilnius, Lithuania). Three reference bands correspond to 3,1 and $0.5 \mathrm{~kb}$. Control cells (freshly isolated from peripheral blood) were incubated in the same medium without the protease. The data are from 1 representative experiment of 5 performed.

SspB-Induced Neutrophil Death Is Caspase as well as Syk Tyrosine Kinase Independent and Is Executed via Cytoskeletal Changes

In addition to caspases, Syk tyrosine kinase and the cytoskeleton also play a crucial role in apoptotic cell death. To elucidate which of the apoptotic pathways is activated

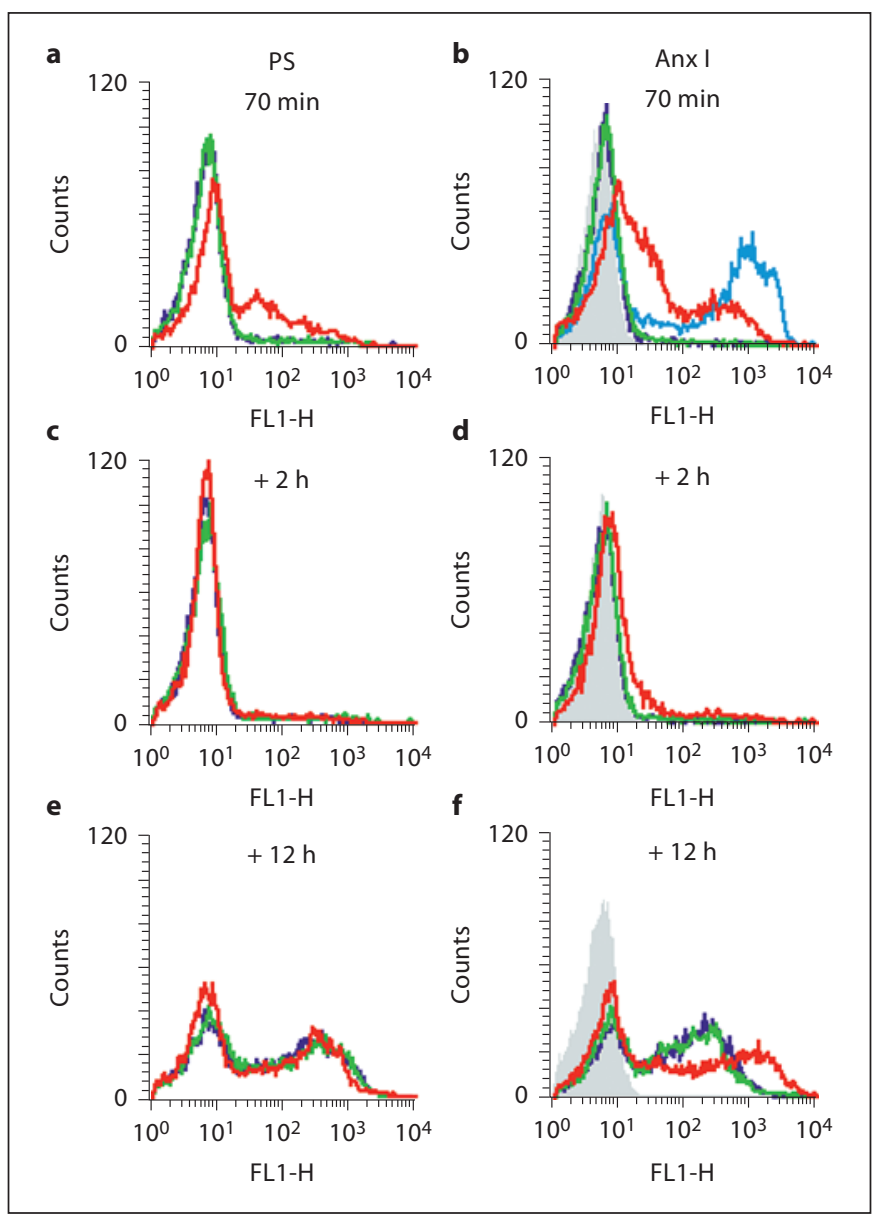

Fig. 3. Presence of serum reverses $\mathrm{SspB}$-induced exposure of PS and AnxI on the outer leaflet of neutrophil cytoplasmic membrane. Neutrophils were preincubated with $100 \mathrm{nM}$ SspB, after which the enzyme was removed and cells were incubated for 2 and $12 \mathrm{~h}$ in medium with $2 \%$ human serum. Exposure of PS and AnxI was measured immediately (a and b), $2 \mathrm{~h}$ (c and $\mathbf{d}$ ) and $12 \mathrm{~h}$ (e and f) after $70 \mathrm{~min}$ of treatment with $\mathrm{SspB}$. Green represents fluorescence intensity of control neutrophils, red represents SspB-treated neutrophils, dark blue represents neutrophils incubated with dithiothreitol, an activation factor for SspB, pale blue represents spontaneously apoptotic neutrophils (aged $24 \mathrm{~h}$ ) which served as a positive control for AnxI exposure and gray represents the autofluorescence of control cells. The results of 1 representative experiment of 3 performed are presented.

by SspB in neutrophils, these cells were preincubated with the pancaspase inhibitor zVAD-fmk, piceatannol, a Syk tyrosine kinase inhibitor, and cytochalasin $\mathrm{D}$, a wellknown actin filament-polymerization blocker, prior to SspB exposure. As shown in figure 4, only cytochalasin D efficiently blocked SspB-induced neutrophil death, suggesting that cell death is mediated via effects on the cytoskeleton. This observation, together with our results 
showing that SspB blocked the spontaneous apoptotic laddering of DNA in neutrophils without inducing alterations in mitochondrial membrane potential, strongly supports our contention that SspB triggers an atypical apoptotic-like cell death in human neutrophils. The protective effect of $z$-VAD-fmk at a $150-\mu \mathrm{M}$ concentration is most likely due to the nonspecific blocking of caspase-independent biological processes within neutrophils.

\section{IgG and Their Fc Fragments Block SspB-Induced \\ Neutrophil Death}

The protection of neutrophils and monocytes by human serum from SspB-induced cell death prompted us to identify factor(s) responsible for this effect. To this end, pooled serum was fractionated by ammonium sulfate precipitation, followed by separation using ion exchange chromatography. Surprisingly, an isolated protein that protected neutrophils from SspB-induced cell death was identified as human IgG. The protective effect of IgG was further substantiated by the preincubation of neutrophils with purified IgG and their Fc fragments, before exposure to SspB. In contrast to predominantly $\mathrm{AnxV}$-positive and PI-permeable cells treated with SspB in the absence of IgG or Fc fragments, the presence of these proteins protected neutrophils from the adverse effects of SspB, with around $80 \%$ of cells appearing healthy and functional (AnxV and PI negative; fig. 5a). These results demonstrate that IgG and their Fc fragments block the SspBinduced death of human neutrophils.

It is known that staphylococcal protein A (SpA), present on the surface of the pathogen, binds IgG via Fc fragments, thus protecting bacterial cells from phagocytosis by neutrophils and increasing their virulence $[26,27]$. To further confirm the protective activity of IgG, cells were preincubated with $\mathrm{SspB}$ in the presence of human serum previously adsorbed with protein A-Sepharose. As shown in figure $5 \mathrm{~b}$, serum treatment with protein A significantly decreased the number of PI- and AnxV-positive cells in comparison to control samples incubated with SspB in medium with albumin alone. This protective effect was less profound than that exerted by untreated serum, apparently due to the incomplete neutralization of IgG by protein A. The relatively high SD values of neutrophils preincubated with SspB in the presence of protein ASepharose-absorbed serum most likely resulted from the variable susceptibility of cells from individual donors and variations in the residual IgG content in individual batches of protein A-pretreated serum.

Taken together, these results strongly argue that IgG is the sole factor protecting neutrophils from the death- inducing activity of $\mathrm{SspB}$, and suggests that $\mathrm{SpA}$ may intensify this effect by neutralizing IgG on human phagocytes at sites of infection.

\section{SspB Decreases the Surface Expression of CD16}

(Fc $\gamma R I I I)$ and CD11b/CD18 (Mac-1) Integrin on

Neutrophils and Monocytes

IgG apparently mediate the protection of neutrophils and monocytes against $\mathrm{SspB}$, suggesting that the binding of IgG by Fc receptors on phagocytes provides a signal to neutralize the lethal effects of the protease. Therefore, the expression of Fc $\gamma$ RIII (CD16) on neutrophils was investigated. It was shown that SspB treatment decreased the surface expression of receptor CD16 on neutrophils in a proteolytic activity-dependent manner (fig. 6a). This effect was abrogated by the presence of IgG, suggesting that IgG binding to CD16 protects the receptor from proteolytic degradation.

Treatment with SspB also diminished surface expression of the CD11b $\left(\alpha_{M}\right)$ subunit of the Mac-1 receptor on phagocytes (fig. 6b). Surprisingly, CD11b surface exposure was also affected by the inactive C24A variant of $\mathrm{SspB}$. Interestingly, the observed changes in receptor expression profiles clearly differed between cells treated with the active and inactive protease (fig. 6b). This suggests a distinct molecular mechanism of action for these 2 forms of the enzyme. Significantly, the presence of 2 major Mac-1 ligands (ICAM-1 and fibrinogen) during protease treatment did not block the effect of SspB on CD11b expression (data not shown).

\section{Discussion}

In this paper, we describe a novel antiphagocytic strategy of S. aureus, which is independent of toxins and benign for other cells. This strategy, based on the specific proteolysis of surface receptors, enables $S$. aureus to neutralize cellular branches of innate immunity without causing excessive tissue damage and necrotic inflammation triggered by toxins. This is achieved by SspB, a cysteine protease secreted by $S$. aureus, which, in the absence of human serum, provoked necrotic and apoptotic-like forms of death in human neutrophils and monocytes. SspB induced exposure of PS and AnxI, 2 major markers of apoptosis, as well as PI permeability, which is typical of necrosis. Importantly, the effect of this protease on cell death was reversible in the presence of human serum, and dependent on proteolytic activity, since an inactive, recombinant form of SspB (C24A) was unable to elicit the observed effects. 


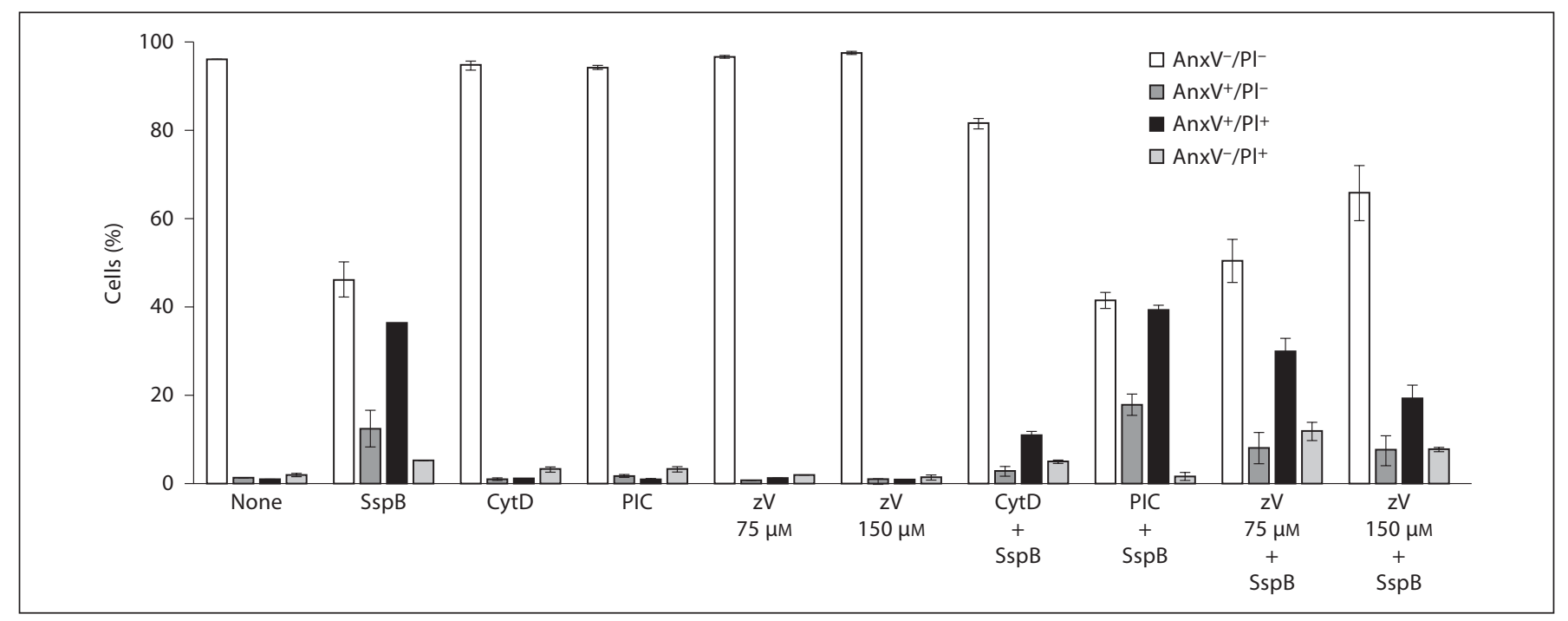

Fig. 4. SspB induces neutrophil death in a caspase- and Syk tyrosine kinase-independent manner via effects on the actin cytoskeleton. Neutrophils were preincubated in medium with $1 \%$ BSA for $15 \mathrm{~min}$ in the presence of zVAD-fmk (zV; 75 or $150 \mu \mathrm{M})$, piceatannol (PIC; $20 \mu \mathrm{M})$ and cytochalasin D (Cyt D; $100 \mu \mathrm{M})$ prior to SspB

Recently, several forms of apoptotic-like neutrophil death have been described, including caspase-independent cell death [28] and tumor necrosis factor- $\alpha$-induced apoptosis, which occurs without DNA fragmentation, but is dependent on mitochondria-derived reactive oxygen species [29]. In this context, it is interesting to note that cytochalasins, which are known to induce NADPH oxidase activity [30], efficiently protected neutrophils and monocytes against the cytotoxic effect of SspB in this study. This effect suggests that the $S s p B$ proapoptotic pathway is independent of NADPH oxidase activity. In keeping, von Bernuth et al. [31] showed no difference in the susceptibility to $S$. aureus phagocytosis-induced apoptosis of monocytes from patients with chronic granulomatous disease, where patients lack NADPH oxidase, or from healthy donors. This finding corroborates well with our results that although neutrophils express 10 times more NADPH oxidase than monocytes [32], there was no difference in the loss of viability in these cells following SspB treatment. Cumulatively, these results undermine the dependence of bacterial-induced cell death on free radicals.

This protection by cytochalasins suggests a novel, $S$. aureus-induced cell death pathway, apparently unrelated to the pathway previously described for neutrophils [33]. It is known that impaired actin polymerization results in the persistent expression of an altered CD11b, which is incubation (100 nM, $75 \mathrm{~min})$. Control or treated cells were stained with FITC-labeled AnxV and PI, followed by flow cytometry analysis to determine the percentage of AnxV-/PI-, AnxV+/PI-, $\mathrm{AnxV}+/ \mathrm{PI}+$ and $\mathrm{AnxV}-/ \mathrm{PI}+$ cells. For details, see legend of figure 1 . Data are the means \pm SD from 2 independent experiments. unable to promote adherence $[34,35]$. In our opinion, the altered overexpressed CD11b may confer resistance to SspB, thus providing a basis for the observed effects. Similarly, a subtle difference between CD11b/CD18 (Mac-1) on macrophages and circulating neutrophils and monocytes [8] may provide the molecular basis for the resistance observed of the former phagocytes to SspB.

In human serum, we identified IgG as cytoprotective factors able to prevent cell death, and even rescue cells from the SspB-induced proapoptotic pathway. This protective activity exerted by the Fc fragment of IgG was abrogated by $\mathrm{SpA}$. This important virulence factor of $S$. $a u$ reus binds specifically, and with high affinity, to Fc fragments of IgG. In the context of our results, it is tempting to speculate that part of SpA's pathogenic activity may be related to SspB's effect on phagocytes.

Engagement of the Fc fragment in cytoprotection turned our attention to CD16 (FcyRIII), the major Fc receptor shared by all neutrophils and about $10 \%$ of monocytes $[36,37]$. In the context of the pivotal role of CD11b in SspB-induced cell death, it is important to keep in mind that CD16 forms complex with CD11b and glycosylphosphatidylinositol-anchored CD16 molecules on human neutrophils $[6,7]$. Indeed, active SspB decreased the surface expression of CD16 (Fc $\gamma$ RIII) on neutrophils. The observed decrease was apparently dependent on proteolytic activity, suggesting that CD16 is a substrate for SspB in 


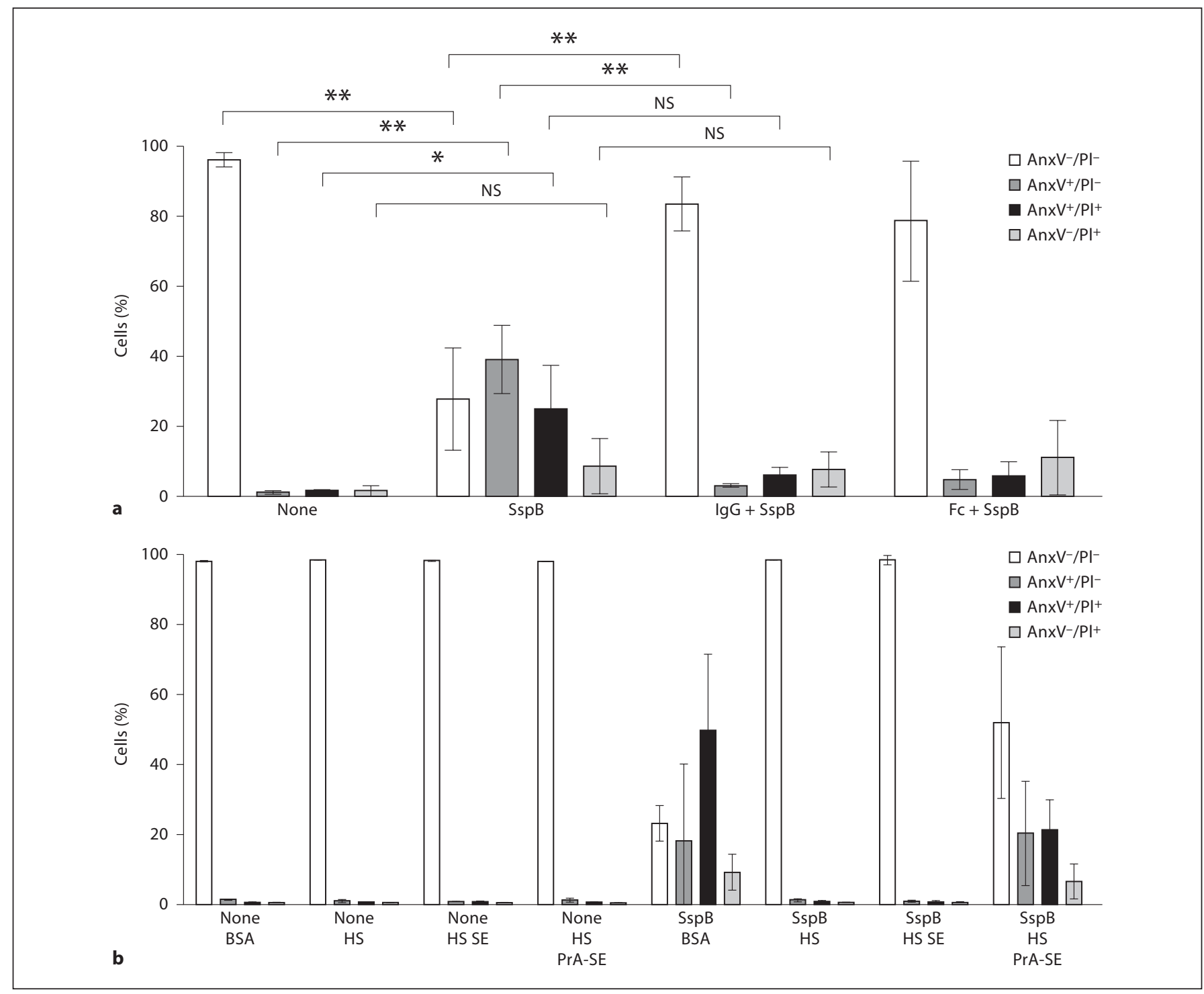

Fig. 5. IgG and IgG-derived Fc fragments abolish SspB-induced death of neutrophils whilst SpA intensifies the effect of the protease. a Neutrophils were preincubated with $\operatorname{IgG}(11 \mathrm{mg} / \mathrm{ml})$ or their Fc fragments $(7 \mathrm{mg} / \mathrm{ml})$ in medium with $1 \%$ BSA for 15 min prior to SspB treatment $(100 \mathrm{nM}, 75 \mathrm{~min})$. NS = Not significant. $\mathbf{b}$ Cells were treated with SspB (100 nM, $75 \mathrm{~min})$ in medium with 2\% BSA, $2 \%$ human serum (HS), $2 \%$ protein A-Sepharose CL 4B-adsorbed

vivo. Purified IgG or Fc fragments prevented CD16 cleavage (data not shown). We assume that the Fc fragment blocked the access of SspB to the cleavage site in CD16. In CD16-negative monocytes, another Fc receptor, Fc $\gamma R \mathrm{RI}$ (CD64), may serve similar functions, as it is colocalized with CD11b in lipid rafts [38]. Indeed, signaling by Fc receptors engages Syk tyrosine kinase [39], and provides mostly anti-apoptotic signals [40]. Surprisingly, piceatan- human serum (HS PrA-SE) or $2 \%$ serum preincubated with Sepharose 4B (HS SE; unspecific binding control). Control or treated cells were stained with FITC-labeled AnxV and PI, followed by flow cytometry analysis to determine the percentage of AnxV-/PI-, AnxV+/PI-, AnxV+/PI+ and AnxV-/PI+ cells. For details, see legend of figure 1. Data are the means \pm SD from 3 (a) and 2 (b) independent experiments.

nol, a specific Syk inhibitor, had no effect on SspB-induced neutrophil death, indicating a Syk tyrosine kinase-independent mechanism of cytoprotection elucidated by IgG.

The effect of SspB on CD11b/CD18 integrin surface expression was seemingly more complex. Although the inactive mutant $(\mathrm{C} 24 \mathrm{~A})$ also caused reduced $\mathrm{CD} 11 \mathrm{~b}$ surface expression on neutrophils and monocytes, the effect was somehow different from that obtained with the ac- 


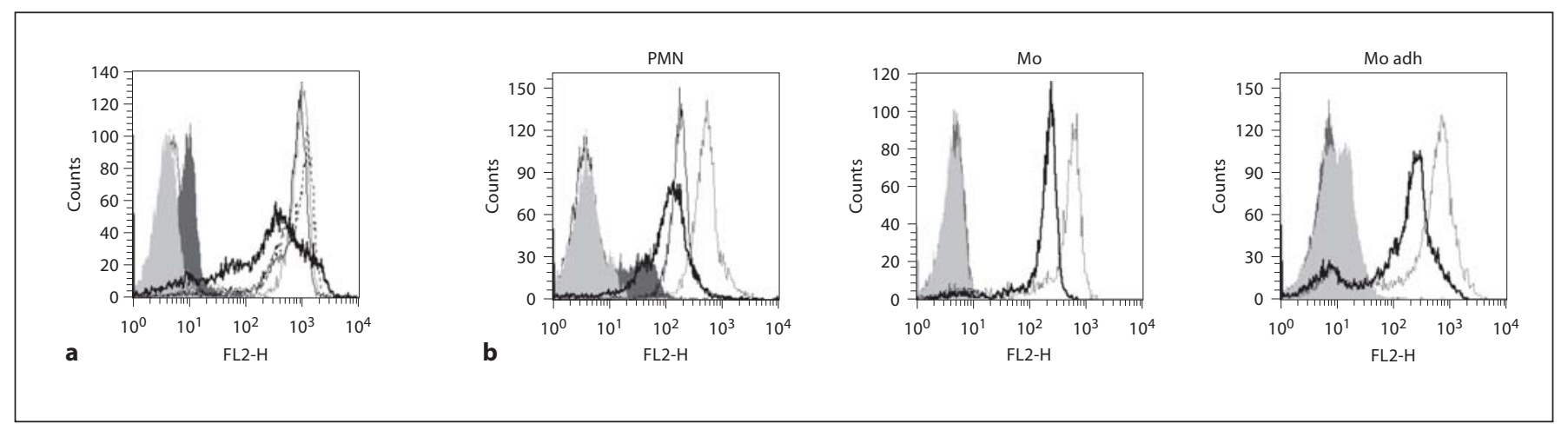

Fig. 6. SspB decreases surface expression of CD16 on neutrophils (a) as well as CD11b/CD18 on both neutrophils and monocytes (b). a Neutrophils were incubated in medium with $1 \%$ BSA with $100 \mathrm{nM}$ active SspB and the inactive recombinant form of the enzyme (C24A), with or without the addition of IgG. Control and treated cells were stained with anti-CD16 fluorescently labeled monoclonal antibody, followed by flow cytometry analysis. The dotted line represents fluorescence intensity of control cells, the thick black line represents neutrophils treated with $100 \mathrm{~nm}$ SspB, the dashed line represents cells treated with $100 \mathrm{nM}$ SspB in the presence of IgG and the thin black line represents neutrophils incubated with inactive SspB (C24A). b Neutrophils (PMN) and ad-

tive enzyme and, significantly, was not accompanied by cell death. This suggests internalization of Mac-1 by unknown mechanisms, probably similar to that activated by treatment with PMA [41]. Neither Mac-1 clustering ligands (ICAM-1 and fibrinogen; data not shown) nor adherence protected monocytes from SspB-mediated proteolytic shedding of CD11b molecules. Cumulatively, these results allow us to conclude that: (1) proteolytic cleavage of integrin $\mathrm{CD} 1 \mathrm{lb}$ provides a death signal to cells; (2) the cleavage site is not hindered by clustering ligands or binding to the substratum, although it is blocked by lateral interaction with CD16 (and probably by CD64 on $\mathrm{CD}_{16}^{-} \mathrm{Mo}$ ); (3) CD16 is protected by bound Fc fragments, and this complex is relatively resistant to SspB.

In light of the accumulated data, it is clear that $\beta_{2}$ integrins, especially CD11b/CD18 (Mac-1 and CR3), are multifunctional surface molecules, regulating neutrophil apoptosis. The CD11b activity is bidirectional and dependent on the ligand. Engagement of Mac-1 by ICAM-1 or fibrinogen appears to signal survival cues in neutrophils. In contrast, Mac-1-dependent phagocytosis of complement-opsonized pathogens triggers rapid neutrophil apoptosis, accompanied by NADPH oxidase activation and reactive oxygen species production [21-23]. Here we show a novel CD11b-dependent activity inducing atypical apoptosis upon proteolytic cleavage by this staphylo- herent (Mo adh) as well as nonadherent monocytes (Mo) were incubated in medium with $1 \%$ BSA with either $100 \mathrm{nM}$ active SspB or the inactive form of SspB, C24A (only for PMN), and stained using an anti-CD11b fluorescently labeled monoclonal antibody, followed by flow cytometry analysis. The dotted line represents fluorescence intensity of control cells, the thick black line represents cells treated with $100 \mathrm{nM} \mathrm{SspB}$, the thin black line (only for $\mathrm{PMN}$ ) represents cells incubated with inactive SspB (C24A). Light and dark gray areas represent autofluorescence of control and SspB-treated cells, respectively $(\mathbf{a}, \mathbf{b})$. The results of 1 representative experiment of 3 performed are presented.

coccal protease. At sites of infection, this process may reduce the number of functional phagocytes, thus facilitating the colonization and dissemination of $S$. aureus.

\section{Acknowledgements}

Ms. Ewa Marewicz (Jagiellonian University, Kraków) is thanked for excellent counterflow elutriation of monocytes. Dr. Les Shaw (University of South Florida, Tampa, Fla., USA) and Ky-Anh Nguyen (Westmead Centre for Oral Health, Sydney, N.S.W., Australia) are acknowledged for fruitful discussion and critical reading of the manuscript. This work was supported by grants N301 035 32/1414, N N301 031534, N N303 291934 and N N301 164235 to J.S., K.G., M.B. and J.P., respectively, from the Ministry of Science and Higher Education (Warsaw, Poland) and institutional funds (BW9 and DS9) from the Faculty of Biochemistry, Biophysics and Biotechnology, Jagiellonian University, Krakow, Poland.

References
1 Mayer-Scholl A, Averhoff P, Zychlinsky A: How do neutrophils and pathogens interact? Curr Opin Microbiol 2004;7:62-66.

2 Liese JG, Jendrossek V, Jansson A, Petropoulou T, Kloos S, Gahr M, Belohradsky BH: Chronic granulomatous disease in adults. Lancet 1996;347:220-223.

-3 Greenberg S, Grinstein S: Phagocytosis and innate immunity. Curr Opin Immunol 2002, 14:136-145. 
4 Greenberg S, Chang P, Silverstein SC: Tyrosine phosphorylation of the $\gamma$ subunit of $\mathrm{Fc} \gamma$ receptors, $\mathrm{p} 72^{\text {Syk }}$ and paxilin during Fc-receptor-mediated phagocytosis in macrophages. J Biol Chem 1994; 269: 3897-902.

-5 Mitchell MA, Huang MM, Chien P, Indik ZK, Pan XQ, Schreiber AD. Substitutions and deletions in the cytoplasmic domain of the phagocytic receptor Fc $\gamma$ RIIA: effect on receptor tyrosine phosphorylation and phagocytosis. Blood 1994; 84: 1753-1759.

6 Zhou MJ, Brown EJ. CR3 (Mac-1, $\alpha_{M} \beta_{2}$, $\mathrm{CD} 11 \mathrm{~b} / \mathrm{CD} 18)$ and $\mathrm{Fc} \gamma \mathrm{RIII}$ cooperate in generation of a neutrophil respiratory burst: requirement for FcyRII and thyrosine phosphorylation. J Cell Biol 1994; 125: 1407-1416.

7 Stockl J, Majdic O, Pickl WF, Rosenkranz A, Prager E, Gschwantler E, Knapp W: Granulocyte activation via a binding site near the C-terminal region of complement receptor type $3 \alpha$-chain (CD11b) potentially involved in intramembrane complex formation with GPI-anchored Fc $\gamma$ IIIB (CD16) molecules. J Immunol 1995; 154: 5452-5463.

8 Jongstra-Bilen J, Harrison R, Grinstein S: Fc $\gamma$-receptors induce Mac-1 (CD11b/CD18) mobilization and accumulation in the phagocytic cup for optimal phagocytosis. J Biol Chem 2003; 278: 45720-45729.

9 Lowy FD: Staphylococcus aureus infections. N Engl J Med 1998; 339: 520-532.

10 Diekema DJ, Pfaller MA, Schmitz FJ, Smayevsky J, Bell J, Jones RN, Beach M, SENTRY Participants Group: Survey of infections due to Staphylococcus species: frequency of occurrence and antimicrobial susceptibility of isolates collected in the United States, Canada, Latin America, Europe, and the Western Pacific region for the SENTRY Antimicrobial Surveillance Program, 19971999. Clin Infect Dis 2001; 32:S114-S132.

11 Archer GL: Staphylococcus aureus: a wellarmed pathogen. Clin Infect Dis 1998; 26: 1179-1181.

12 Coulter SN, Schwan WR, Ng EY, Langhorne $\mathrm{MH}$, Ritchie HD, Westbrock-Wadman S, Hufnagle WO, Folger KR, Bayer AS, Stover CK: Staphylococcus aureus genetic loci impacting growth and survival in multiple infection environments. Molecular Microbiology 1998; 30: 393-404.

13 Menzies BE, Kourteva I: Internalization of Staphylococcus aureus by endothelial cells induces apoptosis. Infect Immun 1998; 66: 5994-5998.

14 Bayles KW, Wesson CA, Liou LE, Fox LK, Bohach GA, Trumble WR: Intracellular Staphylococcus aureus escapes the endosome and induces apoptosis in epithelial cells. Infect Immun 1998; 66: 336-342.

15 Baran J, Guzik K, Hryniewicz W, Ernst M, Flad HD, Pryjma J: Apoptosis of monocytes and prolonged survival of granulocytes as a result of phagocytosis of bacteria. Infect Immun 1996; 64: 4242-4248.
16 Bantel H, Sinha B, Domschke W, Peters G, Schulze-Osthoff K, Janicke RU: $\alpha$-Toxin is a mediator of Staphylococcus aureus-induced cell death and activates caspases via the intrinsic death pathway independently of death receptor signaling. J Cell Biol 2001; 155: 637648.

17 Essmann F, Bantel H, Totzke G, Engels IH, Sinha B, Schulze-Osthoff K, Janicke RU: Staphylococcus aureus $\alpha$-toxin-induced cell death: predominant necrosis despite apoptotic caspase activation. Cell Death Differ 2003; 10: 1260-1272.

18 Genestier AL, Michallet MC, Prevost G, Bellot G, Chalabreysse L, Peyrol S, Thivolet F, Etienne J, Lina G, Vallette FM, Vandenesch F, Genestier L: Staphylococcus aureus Panton-Valentine leukocidin directly targets mitochondria and induces Bax-independent apoptosis of human neutrophils. J Clin Invest 2005 ; 115: 3117-3127.

19 Hofer MF, Newell K, Duke RC, Schlievert PM, Freed JH, Leung DY: Differential effects of staphylococcal toxic shock syndrome toxin-1 on B cell apoptosis. Proc Natl Acad Sci USA 1996; 93: 5425-5430.

20 Shaw L, Golonka E, Potempa J, Foster SJ: The role and regulation of the extracellular proteases of Staphylococcus aureus. Microbiology 2004; 150: 217-228.

21 Mayadas TN, Cullere X: Neutrophil $\beta_{2}$ integrins: moderators of life or death decisions. Trends Immunol 2005; 26: 388-395.

22 Coxon A, Rieu P, Barkalow FJ, Askari S, Sharpe AH, von Andrian UH, Arnaout MA, Mayadas TN: A novel role for the $\beta_{2}$ integrin CD11b/CD18 in neutrophil apoptosis: a homeostatic mechanism in inflammation. Immunity 1996; 5: 653-666.

23 Walzog B, Jeblonski F, Zakrzewicz A, Gaehtgens $\mathrm{P}: \beta_{2}$-integrins $(\mathrm{CD} 11 / \mathrm{CD} 18)$ promote apoptosis of human neutrophils. FASEB J 1997; 11: 1177-1186.

24 Arvidson S, Holme T, Lindholm B: Studies on extracellular proteolytic enzymes from Staphylococcus aureus. I. Purification and characterization of one neutral and one alkaline protease. Biochim Biophys Acta 1973; 302: 135-148.

25 Yang M, Chang H, Chen R, Yang KD: Reversible phosphatidylserine expression on blood granulocytes related to membrane perturbation but not DNA strand breaks. Leukoc Biol 2002; 71: 231-237.

26 Palmqvist N, Foster T, Tarkowski A, Josefsson E: Protein A is a virulence factor in Staphylococcus aureus arthritis and septic death. Microb Pathog 2002; 33: 239-249.

27 DeDent AC, McAdow M, Schneewind O: Distribution of protein A on the surface of Staphylococcus aureus. J Bacteriol 2007; 189: 4473-4484.

28 Park HY, Song MG, Lee JS, Kim JW, Jin JO, Park JI, Chang YC, Kwak JY: Apoptosis of human neutrophils induced by protein phosphatase $1 / 2 \mathrm{~A}$ inhibition is caspase-independent and serine protease dependent. J Cell Physiol 2007; 212: 450-462.
29 Maianski NA, Roos D, Kuijpers TW: Tumor necrosis factor $\alpha$ induces a caspase-independent death pathway in human neutrophils. Blood 2003; 101: 1987-1995.

30 Okamura N, Hanakura K, Kodakari M, Ishibashi S: Cooperation of cytochalasin D and anti-microtubular agents in stimulating superoxide anion production in polymorphonuclear leukocytes. J Biochem 1980; 88: 139144 .

31 von Bernuth H, Kulka C, Roesler J, Gahr M, Rösen-Wolff A: NADPH oxidase is not required for spontaneous and Staphylococcus aureus-induced apoptosis of monocytes. Ann Hematol 2004; 83: 206-211.

32 Emmendorffer A, Nakamura M, Rothe G, Spiekermann K, Lohmann-Matthes ML, Roesler J: Evaluation of flow cytometric methods for diagnosis of chronic granulomatous disease variants under routine laboratory conditions. Cytometry 1994; 18: 147155 .

33 Lundqvist-Gustafsson H, Norrman S, Nilsson J, Wilsson A: Involvement of p38-mitogen-activated protein kinase in Staphylococcus aureus-induced neutrophil apoptosis. J Leukoc Biol 2001; 70: 642-648.

34 Anderson SI, Hotchin NA, Nash GB: Role of the cytoskeleton in rapid activation of CD11b/CD18 function and its subsequent downregulation in neutrophils. J Cell Sci. 2000; 113: 2737-2745.

35 Advani A, Marshall SM, Thomas TH: Impaired neutrophil actin assembly causes persistent CD11b expression and reduced primary granule exocytosis in type II diabetes. Diabetologia 2002; 45: 719-727.

36 Passlick B, Flieger D, Ziegler-Heitbrock HW: Identification and characterization of a novel monocyte subpopulation in human peripheral blood. Blood 1989; 74: 2527-2534.

37 Belge KU, Dayyani F, Horelt A, Siedlar M, Frankenberger M, Frankenberger B, Espevik T, Ziegler-Heitbrock L: The proinflammatory $\mathrm{CD} 14+\mathrm{CD} 16+\mathrm{DR}++$ monocytes are a major source of TNF. J Immunol 2002; 168: 3536-3542.

38 Wolf Z, Orso E, Werner T, Klunemann HH, Schmitz G: Monocyte cholesterol homeostasis correlates with the presence of detergent resistant membrane microdomains. Cytometry A 2007; 71: 486-494.

39 Nimmerjahn F, Ravetch JV: Fc $\gamma$ receptors: old friends and new family members. Immunity 2006; $24: 19-28$.

40 Yousefi S, Hoessli DC, Blaser K, Mills GB, Simon HU: Requirement of Lyn and Syk tyrosine kinases for the prevention of apoptosis by cytokines in human eosinophils. J Exp Med 1996; 183: 1407-1414.

41 Davey PC, Zuzel M, Kamiguti AS, Hunt JA, Aziz KA: Activation-dependent proteolytic degradation of polymorphonuclear CD11b. Br J Haematol 2000; 111: 934-942. 